\title{
EDUCAÇÃO AMBIENTAL E OCUPAÇÃO DE ESPAÇOS EM INSTITUIÇÕES DE ENSINO
}

\author{
Artur Alves Farias Junior ${ }^{1}$
}

RESUMO: Instituições de Ensino possuem papel fundamental ao longo da história por sua transmissão do conhecimento científico, sendo este, em maior parte, de sua própria produção. Nessa perspectiva, acredita-se que através da educação, a sensibilização para as pautas ambientais seja despertada e disseminada. Embora desempenhe papel de destaque nessa busca, a educação como instrumento solo não chegará ao objetivo e para além de atividades de educação ambiental, é necessário naturalizar espaços integradores sociais à sustentabilidade no dia a dia das instituições. Deste modo, o presente artigo trata da importância da sensibilização para essa temática, bem como sua relevância como instrumento de construção fornecendo uma proposta de espaço integrador social à sustentabilidade para a comunidade do Campus Aracaju, do Instituto Federal de Educação, Ciência e Tecnologia de Sergipe (IFS). Esta proposta, além de possibilitar uma maior sensibilização para a agenda ambiental na comunidade, chama atenção para mais diálogo acerca dessa temática, já que mudanças no layout de espaços, tornando-os mais integradores, contribuem, inclusive, para o desempenho de estudantes e ainda para sua percepção enquanto sujeito ante os outros e a si mesmo.

Palavras-chave: Educação Ambiental. Integração social. Espaço verde.

ABSTRACT: Educational institutions have played a fundamental role throughout history due to their transmission of scientific knowledge, which is, for the most part, their own production. In this perspective, it is believed that through education, awareness of environmental issues is awakened and disseminated. Although it plays a prominent role in this search, education as a solo instrument will not reach its objective and in addition to environmental education activities, it is necessary to naturalize social integrating spaces for sustainability in the institutions' daily lives. Thus, this article deals with the importance of raising awareness of this theme, as well as its relevance as a construction tool providing a proposal for a social integrating space for sustainability for the community of Campus Aracaju, of the Instituto Federal de Educação, Ciência e Tecnologia de Sergipe (IFS). This proposal, in addition to enabling greater awareness of the environmental agenda in the community, calls attention to more dialogue on this topic, since changes in the layout of spaces, making them more integrating, also contribute to the performance of students and even for his perception as a subject before others and himself.

Keywords: Environmental education. Social integration. Green space.

\footnotetext{
I Educador; Especialista em Gestão Ambiental e Segurança do Trabalho (UCAM/RJ). E-mail: arturfarias.aju@hotmail.com
} 


\section{INTRODUÇÃO}

O entendimento da sustentabilidade enquanto definição mais difundida é através da Comissão de Brundtland (1987), a qual considera que o desenvolvimento sustentável deve satisfazer às necessidades da geração presente sem que comprometa as necessidades de gerações futuras. Tal entendimento traz a visão de longo prazo, um dos princípios básicos de sustentabilidade, uma vez que os interesses das próximas gerações devem ser não só observados, mas também analisados e atendidos. Inúmeras definições surgiram e, certamente, outras tantas ainda existirão, mas o eixo em que todas elas convergem é o chamado tripple bottom line, o tripé da sustentabilidade: econômico, ambiental e social. Sendo este último, a dimensão relacionada às qualidades individuais, abrangendo tanto o ambiente interno de uma instituição quanto o externo (ALMEIDA, 2002).

Princípios de sustentabilidade numa instituição podem ser observados através da capacidade de absorção, por meio de suas quatro dimensões: aquisição, assimilação, transformação e exploração, em que esta última, por exemplo, cumpre o papel da capacidade de incorporar o conhecimento adquirido e transformá-lo em rotinas (PICOLI; TAKAHASHI, 20I6). Para Chauvet (2014), essa dinâmica, por sua vez, dará origem à criação ou melhoria de um bem, sistemas, formas organizacionais e competências. Já para Patterson e Ambrosini (2018), a criação de novos recursos acontece pesquisando, assimilando, transformando e interagindo o conhecimento externo com recursos internos e atuando como uma estrutura de processo para a aprendizagem.

De fato, ressignificações ocorrem no momento em que as Instituições de Ensino (IE) apresentam a preocupação com o desenvolvimento sustentável. Embora desempenhe papel de destaque na busca pela sustentabilidade, a educação como instrumento solo não chegará ao objetivo. Deste modo, para além de atividades de educação ambiental no ambiente acadêmico, é necessário um sistema integrado abrangendo impactos causados por suas atividades e naturalizando espaços integradores sociais à sustentabilidade no dia a dia das instituições. $\mathrm{O}$ presente artigo trata da importância da disseminação da sustentabilidade, bem como sua relevância 
como instrumento de construção fornecendo uma proposta de espaço integrador para a comunidade assistida pelo Campus Aracaju, do IFS.

A preservação do meio ambiente está baseada em leis, como é o exemplo da Constituição Federal (CF) de 1988 que, em seu art. 225, tem como propósito regular os direitos ao meio ambiente e assegurar uma boa qualidade de vida para as pessoas, além de atribuir responsabilidades de preservação ao poder público e à sociedade. Entre as muitas responsabilidades do poder público está a de promover a educação ambiental em todos os níveis de ensino, bem como incentivar a sensibilização pública para que ocorra a preservação. Assim, as IE, de um modo geral, devem oferecer disciplinas sobre meio ambiente ou trabalhar tal conteúdo de maneira transversal, ou seja, aplicando-o dentro da realidade das ementas.

Segundo Viegas e Cabral (2015), entre os 26 princípios estabelecidos pela Declaração do Meio Ambiente em Estocolmo, em 1972, especificou-se a inclusão da educação ambiental em todos os níveis de escolaridade, no intuito de estimular a consciência ambiental no decorrer da vida de uma pessoa, o que reflete, deste modo, em suas atitudes e local de trabalho. $\mathrm{O}$ desenvolvimento sustentável coloca em discussão os diversos modos que a sociedade interage com o meio ambiente, seja este o meio natural ou o meio por ela alterado. Vale ressaltar que, apesar da notória necessidade do ser humano de se relacionar com a natureza, esta existe independente da presença humana.

A natureza nos fornece condições favoráveis à vida, tais como: recursos naturais que sustentam a nossa vida social e biológica e, em contrapartida, a sociedade retribui com rejeitos em leitos de rios, descargas de gases estufa na atmosfera, resíduos no solo e diversas atividades extrativistas e predatórias, que mantém o nosso ciclo de vida funcionando (HIGUCHI; AZEVEDO, 2004). A partir desse entendimento, observa-se que surgem relações em constante movimento, ao mesmo tempo em que ocorrem as interações que dão origem à cultura, tecnologia e demais atividades sociais. Tais atividades, no lugar de promover o desenvolvimento igualitário da sociedade, apresentam um quadro de degradação social, enquanto afeta gravemente o meio ambiente. 
Nesse sentido, as IE se destacam com seu papel transformador, ao construir narrativas para a formação do pensamento sustentável, adotando medidas que levam a um sistema de gestão ambiental da própria instituição e que, por sua vez, disseminam conceitos inovadores da consciência sustentável para além de seus muros, ou seja, em toda a comunidade. Apesar de datado de 2008, o IFS, mais precisamente o Campus Aracaju, trata-se de um novo selo para uma IE já existente que funciona desde o início do século XX. Ao passo que ao mesmo tempo que a sociedade evolui, esta instituição também o faz: cresceu e se multiplicou em modalidades, abrangendo atualmente desde o ensino médio técnico integrado até a pós-graduação. Vale lembrar ainda, que esse crescimento de possibilidades e na comunidade assistida esbarram na estrutura oferecida para tal. Seguindo esse raciocínio, pode-se observar a necessidade de ambientes integradores sociais, sobretudo à sustentabilidade, para fortalecer o papel educador e de agente transformador do IFS para sua comunidade.

O crescimento do Campus Aracaju chama atenção para o fato de que à medida que a comunidade cresce, também crescem os problemas para comportá-la. Assim, o tema escolhido e desenvolvido neste artigo, chama atenção para o interesse e a preocupação com as condições de bem-estar da comunidade assistida por esse campus. Diante do exposto, este trabalho tem como objetivo propor a criação de um espaço integrador social à sustentabilidade, a partir de tecnologias, inclusive, capazes de baratear ou excluir o custo de uma reestruturação espacial. O local escolhido está situado entre os pavilhões do Posto Médico e dos laboratórios de Química, espaço este que, apesar de seu desgaste natural, ainda assim, é bastante utilizado para momentos de descanso, estudo e até mesmo almoço, diariamente.

\section{I.I. Práticas sustentáveis e Instituições de Ensino}

As narrativas relacionadas a este tema e associadas às IE, qualquer que seja o enfoque, destacam sua importância no contexto da educação e apontam para a correlação positiva entre elas. Ao realizar uma revisão de trabalhos sobre o efeito da escola no desempenho cognitivo dos alunos, Soares (2004) concluiu que é possível 
melhorar o desempenho dos alunos através da ação sobre as estruturas escolares. Chauí (2003), por sua vez, afirma que uma universidade sustentável auxilia os estudantes na compreensão da degradação do ambiente, estimula-os às práticas sustentáveis e os sensibiliza para as injustiças.

Deste modo, a educação ambiental cumpre seu papel para alimentar o ideal potencial do sujeito, ao mesmo tempo em que opera como importante mediação, transformando em experiências concretas de identificação e subjetivação de indivíduos e coletividades. Ao passo que efetivamente oferece um ambiente de aprendizagem social, instituindo novos modos de ser, compreender e posicionar-se ante os outros e a si mesmo (CARVALHO, 2017). É importante ressaltar ainda a importância da Política Nacional de Resíduos Sólidos (PNRS), instituída pela Lei 12.305/Io (BRASIL, 2010), que discorre acerca do objetivo de suprir necessidades da sociedade que vive sob uma crise ambiental em relação aos resíduos sólidos, sendo assim, um marco normativo.

O Japão, por exemplo, é considerado um dos países pioneiros no movimento da chamada Educação para o Desenvolvimento Sustentável (NOMURA; ABE, 2010). Estes autores destacam a relevância das ações do Estado em universidades japonesas, estimulando lideranças para a sustentabilidade dentro das mesmas, pois como iniciativa essencial para o aperfeiçoamento da área da sustentabilidade, Nomura e Abe (2010) acreditam que, mesmo sendo a educação ambiental já desenvolvida naquele país, tais pesquisas sobre a Educação para o Desenvolvimento Sustentável precisam ser mais difundidas.

Em nível nacional, cabe lembrar do Instituto Nacional de Ensino e Pesquisa Educacionais Anísio Teixeira (INEP), instrumento governamental que, entre outras, trata da sustentabilidade socioambiental nas Instituições de Ensino Superior (IES) e, por ser um instrumento de credenciamento e recredenciamento das IES, exige que estas insiram em suas atividades cotidianas parâmetros ambientais mesmo ainda que de modo geral. Por um lado, através deste instrumento aquelas IES que não estão dispostas a se enquadrar, são forçadas a pelo menos refletir sobre a questão ambiental. Já por outro lado, para as IES que estão mais abertas à 
mudanças, isso pode ser o início de muitas outras ações positivas no que tange a questão ambiental (LIMA, 2017).

Para esta proposta é sugerida a utilização de tecnologias que não só barateiem, mas excluam os custos para as mudanças do layout espacial. E, além disso, entendase a necessidade de buscar, através de reciclagem, produtos chamados críticos, mas de fácil acesso e manuseio, quando se fala de descarte no município de Aracaju: os pneus. Em 2007, a Associação Nacional da Indústria de Pneumáticos (ANIP) criou a Reciclanip, braço sustentável que gerencia o processo de logística reversa dos pneus para a indústria nacional. Segundo informa a ANIP, esta é a maior iniciativa de destinação de pneus inservíveis entre os países da América Latina e conta com pontos pelo Brasil, sendo três em Sergipe (Aracaju, Laranjeiras e Nossa Senhora do Socorro).

Através do Relatório de Pneumáticos, reproduzido pela ANIP (2017), que trata sobre os fabricantes nacionais de pneus, esses destinaram de forma ambientalmente correta 457.533 toneladas de pneus inservíveis em 2016, o correspondente a $65 \%$ dos pneus produzidos. É sabido que o descarte inadequado de pneus ocasiona problemas para o ambiente e para a saúde coletiva, pois quando descartados em pilhas ou em locais não adequados, tornam-se ideais criadouros de insetos, diversos vetores de transmissão de doenças, entre eles o Aedes Aegypti, mosquito transmissor da dengue. Além disso, oferecem risco de incêndio por queimar com facilidade, produzindo fumaça negra, altamente poluidora, podendo ainda causar contaminação de corpos d'água superficiais ou de aquíferos subterrâneos, tornando a água imprópria para o consumo (LEITE, 2017).

Em Aracaju, o recolhimento de pneus usados ou inservíveis acontece sob a responsabilidade da Secretaria Municipal de Saúde de Sergipe, motivada pela preocupação com a proliferação de doenças de veiculação hídrica. Já a Secretaria Municipal de Meio Ambiente, não possui nenhuma ação referente ao tema e associase a esta problemática o fato de não haver nenhuma indústria de manejo alternativo para esse resíduo no estado de Sergipe (SMS, 2016). Trabalhos sobre as ditas boas práticas de sustentabilidade apontam que os estabelecimentos de ensino superior 
sustentáveis se caracterizam por relacionar o tema transversalmente em suas funções de ensino, pesquisa, serviços prestados à sociedade e demais operações (NEJATI; NEJATI, 2012).

\section{Materiais e métodos}

Este trabalho tem caráter descritivo, uma vez que busca, através de informações e estudos bibliográficos, melhor entendimento da proposta apresentada averiguando e comparando narrativas com a realidade do Campus Aracaju, do IFS. De acordo com Prodanov e Freitas (2013), na pesquisa descritiva o pesquisador observa, registra, analisa e confronta realidades, mas sem modificá-las. Para Lakatos e Marconi (2017), a pesquisa bibliográfica trata do levantamento, seleção e documentação da vasta bibliografia já publicada sobre determinado assunto que está sendo pesquisado em livros, revistas, jornais, teses, dissertações.

Desse modo, adotou-se a abordagem qualitativa, não sendo necessária a utilização de técnicas estatísticas, pois se buscou a verificação e identificação de dados não mensuráveis, tendo como objetivo a contribuição para as boas práticas sustentáveis no campus. Tal método, para Lakatos e Marconi (2017), difere do quantitativo principalmente por não empregar instrumentos estatísticos e ter como material básico o emprego de estudos e narrativas, ao nível das relações e dos discursos. O ambiente natural é a fonte para que o pesquisador possa realizar a coleta e análise de dados.

Para além da literatura, realizou-se visitas in loco no intuito de escolher um espaço do campus para aplicação desse trabalho, levando em consideração o desgaste natural e maior circulação diária de pessoas, ou seja, um posicionamento estratégico. Os dados foram interpretados e confrontados, com o auxílio de recursos do Microsoft Word. O processo de análise e interpretação de dados procura satisfazer aos objetivos da pesquisa, verificando e confrontando informações a partir das evidências observadas (PRODANOV; FREITAS, 2013).

Nessa perspectiva, houve ainda a necessidade de registros fotográficos realizados com uma Canon EOS Rebel T6 EF-S (vide Figuras i, 2 e 3), como modo de 


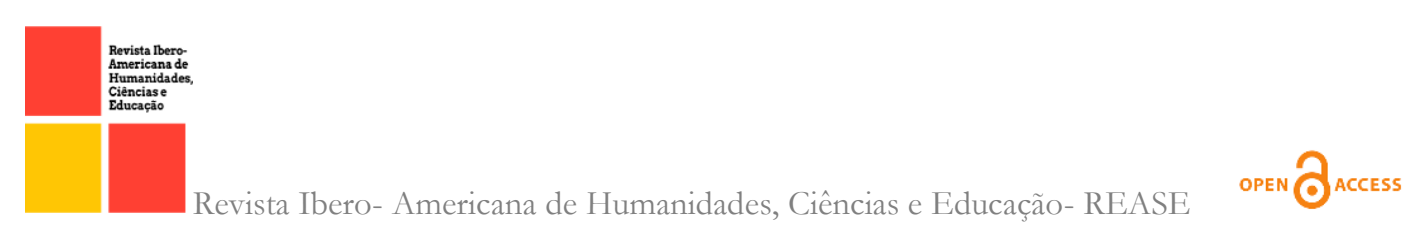

mensurar o espaço escolhido para esta proposta de estudo. Em seguida, uma reunião para ciência e posicionamento do Diretor Geral do campus, Prof. Elber Gama, sobre este trabalho. Para execução da modelagem do projeto, foi escolhido o software considerado mais adequado para tal: Sketch $U p$, próprio para criação de maquetes virtuais e de visualização tridimensional. Logo, mais realista para entendimento deste trabalho.

Através das visitas in loco, observou-se que, apesar de o espaço escolhido apresentar um desgaste natural, ainda assim é bastante utilizado pela comunidade, sobretudo a estudantil, para fins de descanso, lazer e até refeições no seu entorno. A área, compreendida entre o pavilhão do Posto Médico e o pavilhão dos laboratórios de Química, mede 58,5m de comprimento x 4,80m de largura e foi escolhida por vislumbrar um bom ponto de integração social para a comunidade, tanto pelos setores que o cercam, quanto pela proximidade do refeitório (Espaço Leyda Régis), notoriamente um dos ambientes de maior circulação de pessoas ao longo do dia no Campus (Figura I; Figura 2 e Figura 3).

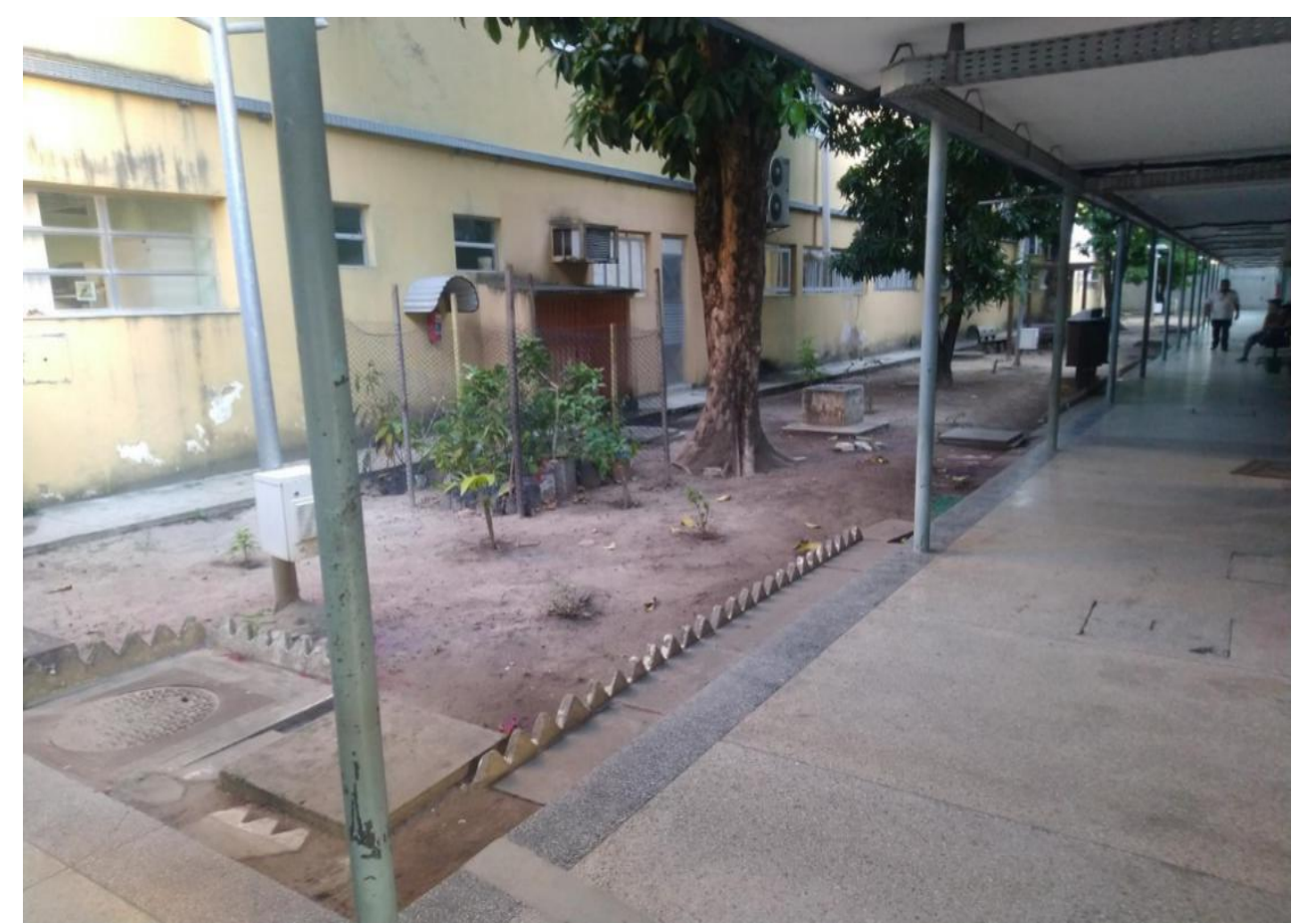

FIGURA r: Visão externa da área.

Fonte: Autor, 2019. 


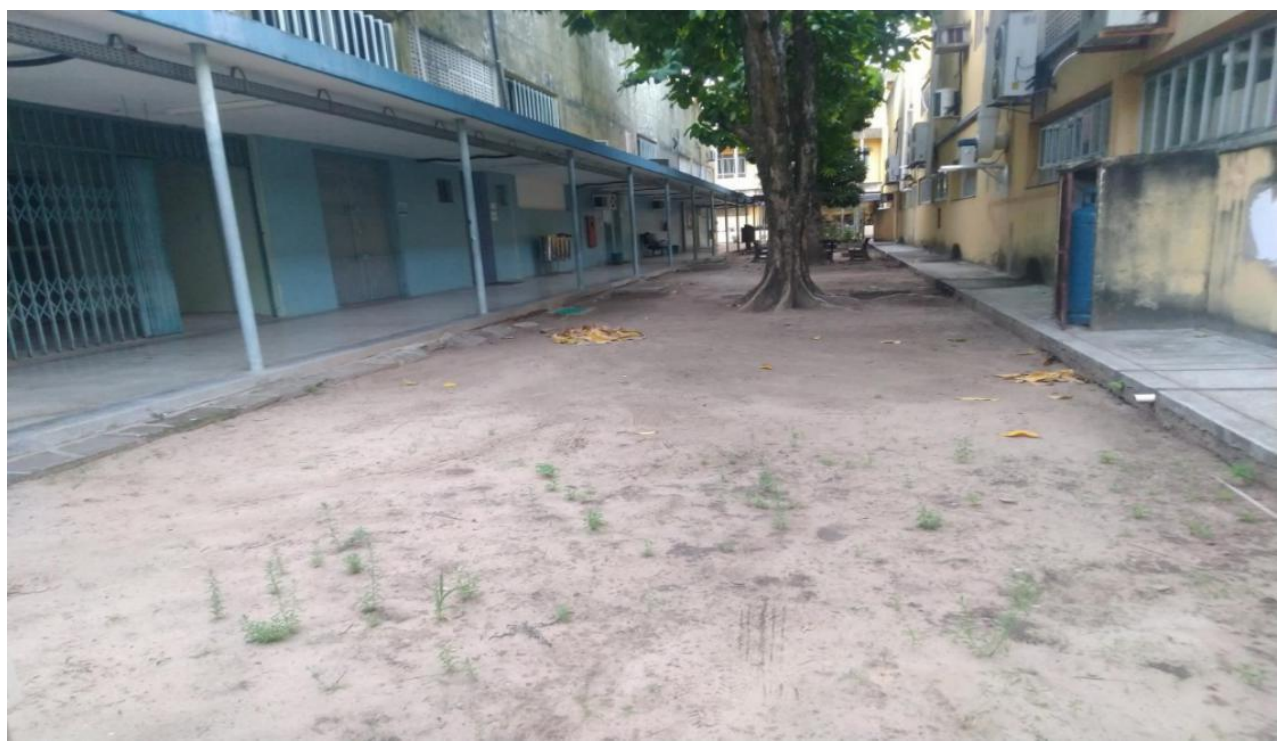

FIGURA 2: Visão interna frontal da área.

Fonte: Autor, 2019.

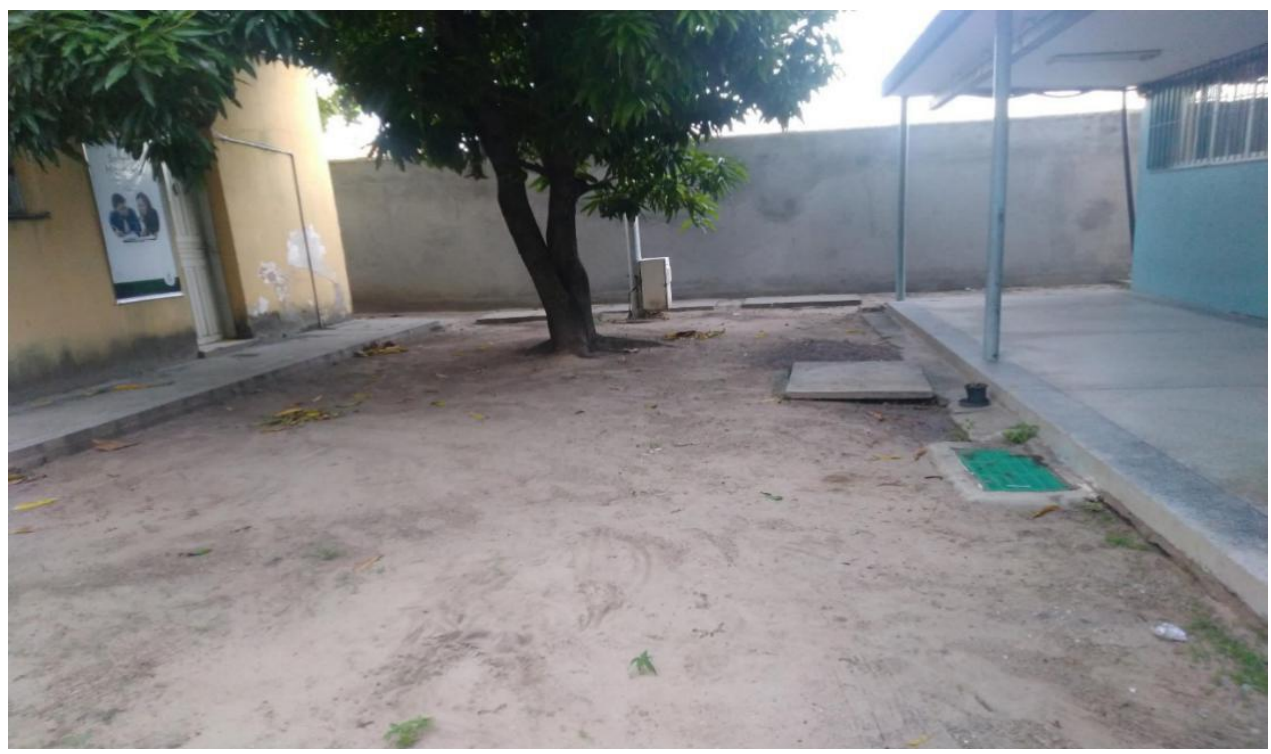

FIGURA 3: Visão interna traseira da área.

Fonte: Autor, 2019.

A escolha do espaço e a proposta deste trabalho também foram discutidas com o Prof. Elber Gama, Diretor Geral do referido campus, que demonstrou interesse pela necessidade de reparos no espaço em questão, bem como pela reformulação do seu layout. Vale ressaltar, que esta última sugere ainda uma melhora significativa no conforto ambiental, o que, por sua vez, resulta em melhores 
condições de bem-estar para a comunidade assistida pelo Campus. Dado o exposto, através de croquis pôde-se delimitar possibilidades para o projeto tais como: quantidade de pneus a serem utilizados e outros materiais acessórios, por exemplo.

A princípio, sugere-se:

- Cobertura de todo o espaço com brita quebrada de baixo custo, o que o tornará mais agradável visualmente;

- Jardins horizontais de pneus serão distribuídos ao longo do espaço, o que possibilitará mais interação da comunidade com o verde;

- Puffs de pneus trançados com fio serão dispostos acompanhados de tonéis ou carretéis, que ganharão uma nova finalidade: a de mesa de apoio;

- O muro localizado ao final deste espaço (vide Figura 3), ganhará arte em spray e um jardim vertical, composto por pneus e correntes de reuso. Para melhor entendimento, segue projeto (vide figura 4) realizado através do software SketchUp, o que possibilita uma explicação mais detalhada:

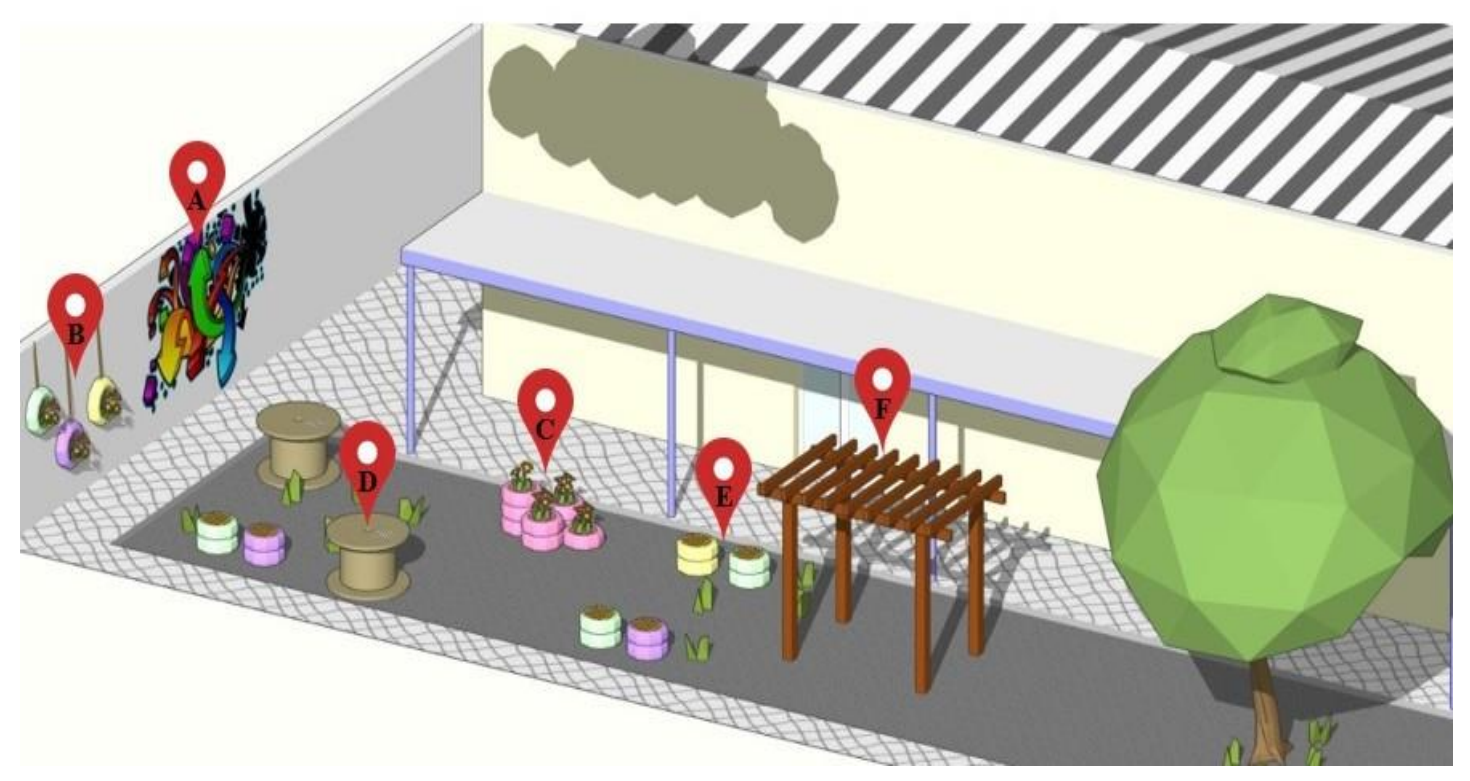

FIGURA 4: Visão traseira do espaço reformado.

Fonte: Autor, 2019. 
Esta perspectiva, demonstra:

A. Arte em spray: sugestão de grafite no muro para maior amplitude do campo de visão a partir do extremo oposto do corredor;

B. Jardim vertical de pneus: numa disposição assimétrica, os pneus são pintados e fixados na parede através de cordas ou correntes de reuso, estas podem ser encontradas em Ferro Velho. Preferência por plantas de fácil manuseio;

C. Jardim horizontal de pneus: disposição em pilhas assimétricas, onde os pneus são pintados e as plantas devem, preferencialmente, ser de fácil manuseio (vide Figura 5);

D. Carretel ou tonel: sob a finalidade de mesa de apoio, estes também podem servir como mesa para jogos de tabuleiro. Para esta última, devem ser pintados e envernizados para melhor conservação, devido a exposição constante (vide Figura 6 e 8 );

E. Puffs de pneus: dispostos em pares ou unitários, devem ser trançados com fio para confeccionar o assento, pintados e furados para evitar acúmulo de água (vide Figura 7);

F. Pergolado: fixado nesse espaço pela gestão do campus durante a produção deste trabalho, pode receber plantas que formam ramagens.

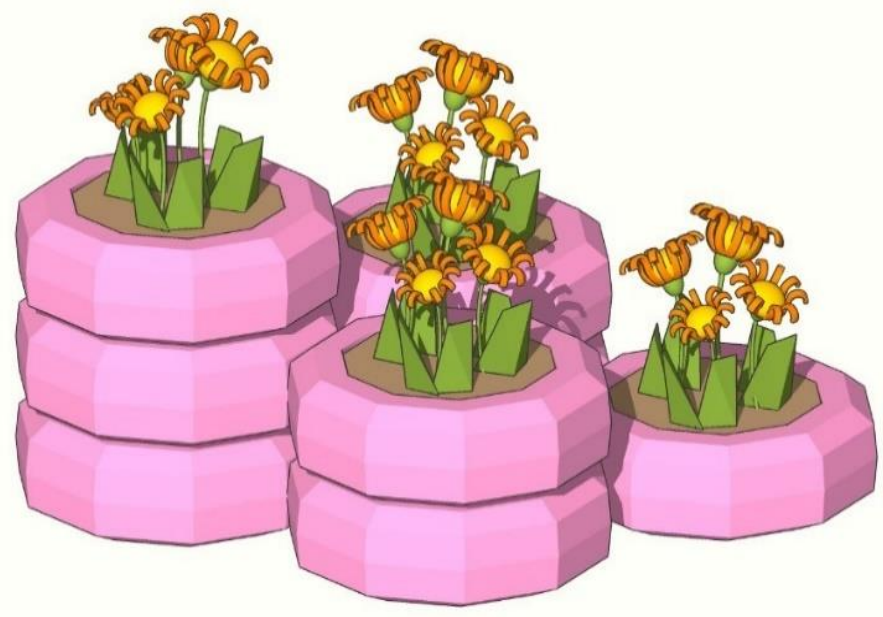

FIGURA 5: Jardim de pneus.

Fonte: Autor, 2019. 


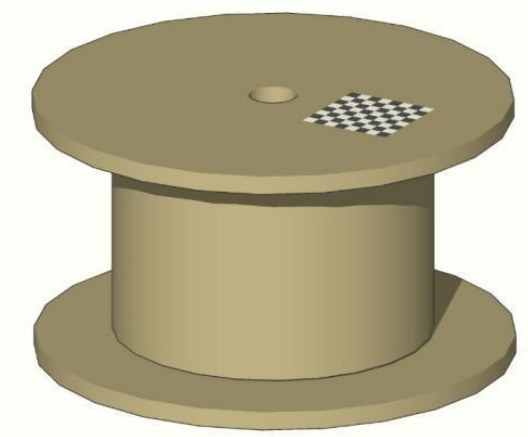

FIGURA 6: Carretel de reuso, como mesa de apoio ou para jogos de tabuleiro. Fonte: Autor, 2019.

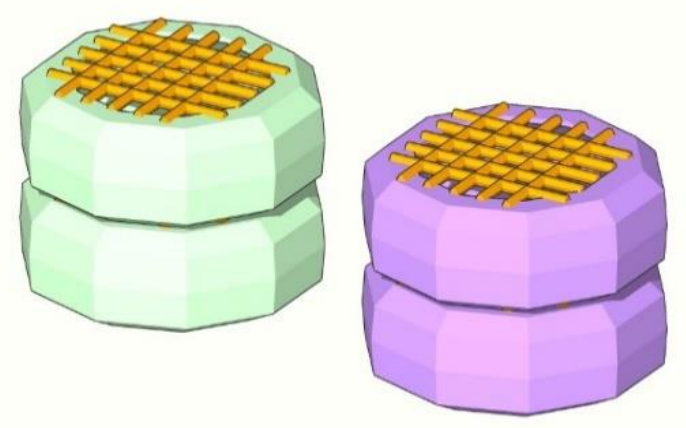

FIGURA 7: Puffs com assento trançado com fio.

Fonte: Autor, 2019.

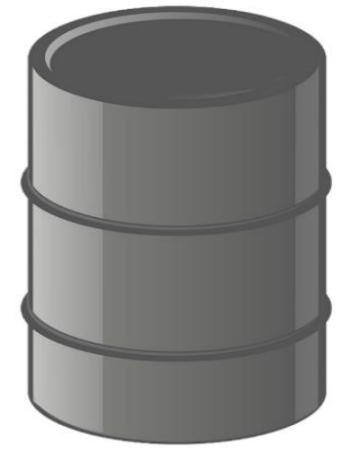

FIGURA 8: Tonel de reuso, como mesa de apoio.

Fonte: Autor, 2019. 


\section{CONSIDERAÇÕES FINAIS}

O presente trabalho procurou contribuir para as boas práticas da sustentabilidade no Campus Aracaju, do Instituto Federal de Sergipe, demonstrando de modo prático que a educação ambiental precisa estar presente não só nos componentes curriculares, mas também em outras rotinas. Este elo, além de possibilitar uma maior sensibilização para a agenda ambiental na comunidade, chama atenção para mais diálogo acerca dessa temática. Mudanças no layout de espaços, tornando-os mais integradores, contribuem, inclusive, para o desempenho de estudantes e ainda para sua percepção enquanto sujeito ante os outros e a si mesmo, como explicam as narrativas deste estudo.

Em suma, no âmbito das IE, estudos demonstram as evidências da incorporação da sustentabilidade tanto no campo do ensino, da pesquisa, da extensão e da inovação, quanto na construção de espaços integradores sociais, com arborização e paisagismo, por exemplo, e que transformam até o que seria considerado resíduo em possibilidades positivas para o conforto ambiental da comunidade. Este trabalho também abre espaço para outros estudos relacionados às problemáticas aqui apresentadas, seja sob outras perspectivas, seja sob outras tecnologias e aprendizados.

\section{REFERÊNCIAS}

ALMEIDA, F. O bom negócio da sustentabilidade. Rio de Janeiro: Nova Fronteira, 2002.

ANIP. Reciclanip e o sucesso da logística reversa. Disponível em: $<$ http://www.anip.org.br/destinacao-ambientalmente-correta/> Acesso em: 1o mai. 2019.

BRASIL. Política Nacional de Resíduos Sólidos - Lei n⿳0 12.305, 02 de agosto de 2010. Disponível em:

〈http://www.planalto.gov.br/ccivil_03/_ato20072010/2010/lei/li2305.h tm〉. Acesso em: 12 abr. 2019.

CARVALHO, I. C. de M. Educação ambiental: A formação do sujeito ecológico. São Paulo: Cortez Editora, 2017. 
CHAUI, M. A universidade pública sob nova perspectiva. Revista Brasileira de Educação, n. 24, p. 5-15, nov./dez. 2003.

CHAUVET, V. Absorptive capacity: Scale development and implications for future research. Management International. Montreal, v. I9, p. I13-130, jan, 2014.

HIGUCHI, M. I. G.; AZEVEDO, G. C. de. Educação como processo na construção da cidadania ambiental. Revista Brasileira de Educação Ambiental, Brasília, n. o, p. 63-70, nov. 2004.

INEP. Instrumento de avaliação institucional externa. Disponível em:< http://download.inep.gov.br/educacao_superior/avaliacao_institucional/instrume ntos/20 I4/instrumento_institucional.pdf>. Acessado em: 18 mai. 2018.

LAKATOS, E. M.; MARCONI, M. de A. F. Fundamentos de metodologia científica. 8a ed. São Paulo: Atlas, 2017.

LEITE, D. T. B. de S. Indicadores de sustentabilidade: Subsídios para o gerenciamento da logística reversa de pós-consumo de pneus inservíveis no município de Aracaju/SE. São Cristóvão: UFS, 2017. Tese Doutorado.

LIMA, R. G. Estimativa da geração de nitrogênio reativo em duas instituições de ensino superior da região Nordeste do Brasil. São Cristóvão: UFS, 2018. Tese Doutorado.

NEJATI, M.; NEJATI, M. Assessment of sustainable university factors from the perspective of university students. Journal of Cleaner Production, v. 48, p. IoI-Io7, 2013.

NOMURA, K.; ABE, O. Higher education for sustainable development in Japan: policy and progress. International Journal of Sustainability in Higher Education, V.II, n. 2, p. 120-I29, 2010.

OLIVEIRA, G. B. de. Uma discussão sobre o conceito de desenvolvimento. Revista da FAE, Curitiba, v.5, n.2, p.4I-48, mai./ago. 2002.

PATTERSON, W. E.; AMBROSINI, V. Configuring absorptive capacity as a key process for research intensive firms. Technovation. Melbourne, v. 36, p. 77-89, 2018.

PICOLI, F. R.; TAKAHASHI, A. A Capacidade de Absorção, Aprendizagem Organizacional e Mecanismos de Integração Social. RAC, Rio de Janeiro, v. 2o, p. I2o, Jan./Fev. 2016.

PRODANOV, C. C.; FREITAS, E. C. de. Metodologia do trabalho científico: Métodos e técnicas da pesquisa e do trabalho $2^{2}$ ed. Novo Hamburgo: Feevale, 2013. Ebook. Disponível em: 〈www.feevale.br/editora>. Acesso em: I8 mai. 2019. 
RECICLANIP. Pontos de coleta no Brasil. Disponível em: 〈http://www.reciclanip.org.br/pontos-de-coleta/coleta-no-brasil/?uf=SE\#>Acesso em: Io mai. 2019.

SECRETARIA MUNICIPAL DE SAÚDE DE ARACAJU-SE. Disponível em: 〈http://www.aracaju.se.gov.br/saude/>. Acesso em: Io mai. 2019.

SOARES, J. F. O efeito da escola no desempenho cognitivo dos alunos. Revista Iberoamericana sobre Calidad, Eficacia y Cambio em Educació, v. 2, p. 97, 2004.

VIEGAS, S. de F. S.; CABRAL, E. R. Práticas de sustentabilidade em instituições de ensino superior: Evidências de mudanças na gestão. Revista Gestão Universitária na América Latina - GUAL, Florianópolis, v.8, jan. 2015. 